\title{
MANIFESTAÇÕES PATOLÓGICAS NA BIBLIOTECA CENTRAL DA UNIVERSIDADE FEDERAL DE SANTA MARIA - RS
}

\author{
AMORETTI, ANA MARIA \\ Mestranda \\ Universidade Federal de Santa Maria \\ Rio Grande do Sul, Brasil \\ amrtorres@hotmail.com \\ PEREIRA, NIANA \\ Mestranda \\ Universidade Federal de Santa Maria \\ Rio Grande do Sul, Brasil \\ niana_fp@hotmail.com
}

\author{
KOZLOSKI, CÁSSIA LAIRE \\ Mestranda \\ Universidade Federal de Santa Maria \\ Rio Grande do Sul, Brasil \\ cakozloski@gmail.com \\ DE LIMA, ROGÉRIO ANTOCHEVES \\ Professor \\ Universidade Federal de Santa Maria \\ Rio Grande do Sul, Brasil \\ rogerio@ufsm.br
}

\section{RESUMO}

Atualmente, a Biblioteca Central da Universidade Federal de Santa Maria, ícone da arquitetura modernista na região central do Rio Grande do sul, apresenta diversas manifestações patológicas que podem comprometer a integridade estética da edificação. Este trabalho objetiva analisar as anomalias de suas fachadas. Para isso aplicou-se etapas de revisão bibliográfica, anamnese e levantamento in loco. Destaca-se, entre os resultados, que as origens de tais anomalias estão relacionadas, provavelmente, ao sistema construtivo, às ações do tempo, a intervenções inadequadas e a problemas de projeto e execução. Esse estudo possibilitou enfatizar a necessidade de planejamento adequado para intervenção construtiva, principalmente em obra de valor histórico. Da mesma forma evidencia a importância de ações de manutenção, a fim de manter as características arquitetônicas da edificação.

Palavras-chave: manifestações patológicas; arquitetura moderna; patrimônio histórico.

\section{ABSTRACT}

The Central Library of the Federal University of Santa Maria, is an icon of the modernist architecture of the central region of Rio Grande do Sul and currently presents many pathological manifestations that can compromise the aesthetic integrity of the building. The present study aims to analyze the anomalies of its façades. In order to do so, the steps of bibliographic review, anamnesis and on-site surveys were carried out. Among the results, it is important to highlight that the origins of such anomalies are probably related to the constructive system, the actions of time, inadequate interventions, the problems of design and execution. This study made it possible to emphasize the need for adequate planning of constructive intervention, mainly when working with sites of historical value. In the same way, it shows the importance of maintenance actions in order to maintain the architectural characteristics of the building. Keywords: pathological manifestations; modern architecture; historical patrimony.

\section{INTRODUÇÃO}

Constituindo um conjunto arquitetônico modernista de grande escala e apresentando conceitos do urbanismo moderno, o campus sede da Universidade Federal de Santa Maria (UFSM), na região Sul do Brasil, atende, atualmente, mais de 29.000 alunos entre os mais de 30.000 totais da instituição (UFSM, 2018). Projetado na década de 1960 pelos arquitetos Oscar Valdetaro e Roberto Nadalutti, características como monumentalidade, separação funcional e tipologias padrão são notáveis na Cidade Universitária (Zampieri, 2011).

O campus da UFSM reproduz em seus edifícios elementos da arquitetura moderna (Zampieri e Machado, 2011), como ocorre na Reitoria e na Biblioteca Central Manoel Marques de Souza, Conde de Porto Alegre. Em especial, a imagem da Biblioteca Central foi utilizada por muitos anos como marca visual em materiais de divulgação da UFSM. A sua volumetria prismática simples com base quadrada e o recuo do pavimento térreo em relação ao volume superior com fechamentos envidraçados, evidencia o ritmo da estrutura de pilares, estabelecendo uma varanda contínua. Essa configuração demarca ainda três volumes distintos, a partir dos níveis de cada pavimento: o subsolo, o térreo e segundo pavimento. Além disso, houve a incorporação de estratégias arquitetônicas bioclimáticas, como elementos de sombreamento inseridos na própria volumetria e um jardim central (Schlee, 2011). 
Em 1967, iniciou-se a construção do atual edificio, concluída em cinco anos e assim inaugurada em 1972 (Arrussul, 2009; Arabidian, et al., 2015). A partir do ano de 1978, iniciaram-se na biblioteca diversos processos de mudanças e melhorias, como a troca de um sistema de empréstimo exclusivo e fechado para um sistema de livre acesso dos usuários ao acervo, que modificou a ocupação de seus espaços. Já na década de 90, com o crescimento do acervo, dentre outros processos de informatização, fez-se necessário um projeto de ampliação de sua área, iniciando as obras em 2010 (Treulieb, 2012). É importante salientar que desde sua inauguração, a biblioteca compartilhou parte de sua área com outros usos, como a Caixa Econômica Federal que permaneceu até setembro de 2011 e, desde 1991, a sede do Curso de Arquitetura e Urbanismo.

Implantada sobre uma área de banhado, com um antigo córrego canalizado próximo ao terreno de implantação (Chiarelli e Michelotti, 2013), a Biblioteca Central demonstra hoje os efeitos de decisões projetuais da época, além do desgaste natural da edificação pela idade. Em 2013, uma obra de ampliação no subsolo do prédio foi finalizada, porém problemas de infiltração vêm impossibilitando o uso efetivo dos espaços.

Desse modo, a atual condição do edifício revela manifestações de umidade, recorrentes tanto no exterior como no interior da edificação, agravadas pela deterioração de materiais e revestimentos, que possibilitam o ingresso de agentes físicos, químicos e biológicos, afetando também o acervo. Como consequência desses eventos, o aspecto externo da edificação transparece relativo esquecimento do local, com visível desvalorização desse marco arquitetônico no Campus da UFSM.

Nesse contexto, essa pesquisa tem por objetivo identificar e classificar as principais manifestações patológicas do prédio da Biblioteca Central Manoel Marques de Souza, Conde de Porto Alegre, da Universidade Federal de Santa Maria, a fim de possibilitar e guiar futuras ações de recuperação. Devido à importância das fachadas na caracterização das edificações relacionadas com o movimento moderno (Muller, 2010), o presente trabalho enfocará somente a análise nas áreas externas do objeto de estudo.

\section{MANIFESTAÇÕES PATOLÓGICAS EM EDIFICAÇÕES}

As áreas externas de edificações são suscetíveis a um processo contínuo de degradação, devido à exposição permanente às intempéries e fatores mecânicos de ocorrência esporádica. Conhecer as diversas causas responsáveis pelo aparecimento de anomalias em fachadas é fundamental para a realização de manutenção apropriada (Madureira et al., 2017), e a prévia identificação e classificação das manifestações patológicas permite maior curacidade nesse processo.

Pode-se dizer que as manifestações patológicas de edificações mais recorrentes são fissuras, queda de reboco, umidade superficial, eflorescências, destacamento de revestimentos e problemas de biodeterioração (Pereira, 2012). Conforme Lersch (2003), tais manifestações costumam apresentar mais de uma causa, ou seja, um conjunto de fatores que levam à degradação. Essas ocorrências podem ser fruto de um baixo nível de controle de qualidade desde as fases de planejamento e projeto até execução e uso, além de condições do meio e problemas nos materiais (Consoli, 2006).

Consoli (2006) lembra que, em geral, os revestimentos não garantem uma vida útil longa para as fachadas. Por isso, manutenções periódicas são essenciais para assegurar a durabilidade e desempenho das mesmas. Para Lima et al. (2004) como medida de conservação de um edifício pode ser necessária até mesmo a substituição parcial ou completa de elementos comprometidos.

\section{METODOLOGIA}

Para o presente estudo, foram avaliadas as fachadas da Biblioteca Central, o que se justifica pela importância de sua preservação como elemento arquitetônico moderno da cidade de Santa Maria.

A metodologia foi dividida em etapas, iniciando-se por um estudo exploratório, bibliográfico e levantamento in loco conforme metodologia utilizada por Sá et al. (2014), seguidas da classificação das manifestações patológicas identificadas. Para essa última etapa, foi realizada uma avaliação incluindo descrição da anomalia bem como as causas prováveis, segundo apresentado por Ferraz et al. (2015). 
Para uma melhor caracterização do objeto de estudo do presente trabalho, realizou-se a análise exploratória, através de pesquisa documental e entrevistas. Desse modo, a anamnese foi realizada compreendendo as etapas da construção, o histórico de uso e reformas.

Simultaneamente, buscou-se identificar principalmente as anomalias mais incidentes em fachadas de edifícios históricos, utilizando, entre outros, os trabalhos de Magalhães et al. (2008) e Beasley (2009). Também se procurou estudar a respeito das principais causas de aparecimento das mesmas.

Como a fase de inspeção foi somente visual, havendo dependência do olhar do investigador, optou-se por utilizar ferramentas que facilitassem e aumentassem a precisão dessa atividade, como recomendado por Pires et al. (2015), tal como Madureira et al. (2017). Assim, para auxiliar no estudo de campo, com base na listagem de anomalias de Oliveira (2013) adaptada à realidade das fachadas da Biblioteca Central, criou-se um sistema de identificação para as mesmas.

Nessa etapa, as manifestações patológicas foram relacionadas adjacentes às opções de pavimento de incidência e orientação solar, para serem assinaladas no levantamento in loco, conforme a tabela apresentada na Figura 1. A identificação das manifestações patológicas foi realizada separadamente para cada fachada, devido às causas poderem estar relacionadas com a incidência solar e a direção dos ventos e chuvas (Mazer et al., 2016).

\begin{tabular}{|c|c|c|c|c|c|c|c|c|c|c|c|c|c|c|c|c|c|c|c|c|c|c|c|c|c|c|c|c|c|c|c|c|c|c|c|c|}
\hline $\begin{array}{l}\text { MANIFESTAČ̃̃O } \\
\text { PATOLOGICA }\end{array}$ & \multicolumn{4}{|c|}{ SUJIDADE } & \multicolumn{4}{|c|}{$\begin{array}{c}\text { DESCOLAMENTO } \\
\text { DE } \\
\text { REVESTIMENTO }\end{array}$} & \multicolumn{4}{|c|}{ FISSURAS } & \multicolumn{4}{|c|}{$\begin{array}{c}\text { DESCOLAMENTO } \\
\text { DA CAMADA DE } \\
\text { PINTURA }\end{array}$} & \multicolumn{4}{|c|}{$\begin{array}{l}\text { MANCHAS DE } \\
\text { OXIDAČ̃̃O }\end{array}$} & \multicolumn{4}{|c|}{ EFLORESCÊNCIA } & \multicolumn{4}{|c|}{ PICHAÇÃO } & \multicolumn{4}{|c|}{ BOLHAS } & \multicolumn{4}{|c|}{ VEGETAÇÃO } \\
\hline \\
\hline \multicolumn{37}{|l|}{ TÉRREO } \\
\hline \multicolumn{37}{|l|}{$2^{\circ}$ PAVIMENTO } \\
\hline $\begin{array}{c}\text { ORIENTAČ̃̃ DA } \\
\text { FACHADA }\end{array}$ & $\mathrm{N}$ & $s$ & L & 0 & $\mathrm{~N}$ & $s$ & $\mathbf{L}$ & 0 & $\mathrm{~N}$ & $s$ & L & 0 & $\mathrm{~N}$ & $S$ & $\mathbf{L}$ & o & $\mathrm{N}$ & $s$ & L & o & $N$ & $s$ & L & o & $\mathrm{N}$ & $s$ & L & 0 & $\mathrm{~N}$ & s & L & o & $\mathrm{N}$ & $\mathrm{s}$ & $\mathbf{L}$ & o \\
\hline
\end{tabular}

Figura 1: Quadro destinado ao levantamento in loco das manifestações patológicas.

Além disso, a investigação das fachadas, no local, foi desenvolvida por três pessoas distintas com formação na área da construção civil. Essa etapa ocorreu em turnos alternados, de maio a junho de 2018, período caracterizado por chuvas e temperaturas amenas e baixas, que podem intensificar algumas anomalias, favorecendo sua identificação. Como ferrametas auxiliares nessa etapa, utilizou-se câmera digital, modelo D3200 da Nikon, e aproximação por zoom óptico.

Durante o estudo de campo, foi necessário complementar a Figura 1 com manifestações patológicas não listadas e incidentes no objeto de estudo. Posteriormente, realizou-se a combinação dos dados, de forma a cobrir o maior número possível de anomalias identificadas.

Por fim, relacionaram-se os itens identificados no levantamento in loco com a revisão bibliográfica e anamnese anterior. Ou seja, as principais manifestações patológicas das fachadas do edifício da Biblioteca Central foram estudadas, sendo possível determinar as possíveis causas das mesmas.

\section{RESULTADOS E DISCUSSÃO}

A Biblioteca Central da UFSM apresenta, atualmente, diversas manifestações patológicas em suas fachadas, que prejudicam o aspecto visual da edificação. A ocorrência das mesmas é apresentada na Figura 2. Identificou-se que a anomalia de maior incidência nas fachadas é a sujidade, ocorrendo de forma acentuada em todas as orientações do segundo pavimento, bem como, em locais específicos do subsolo. Identificou-se que falhas de projeto ou falta de manutenção preventiva em pingadeiras e rufos são as possíveis causas do aparecimento de sujidades nesses pontos, pois possibilitam o escorrimento da água da chuva pela fachada. 


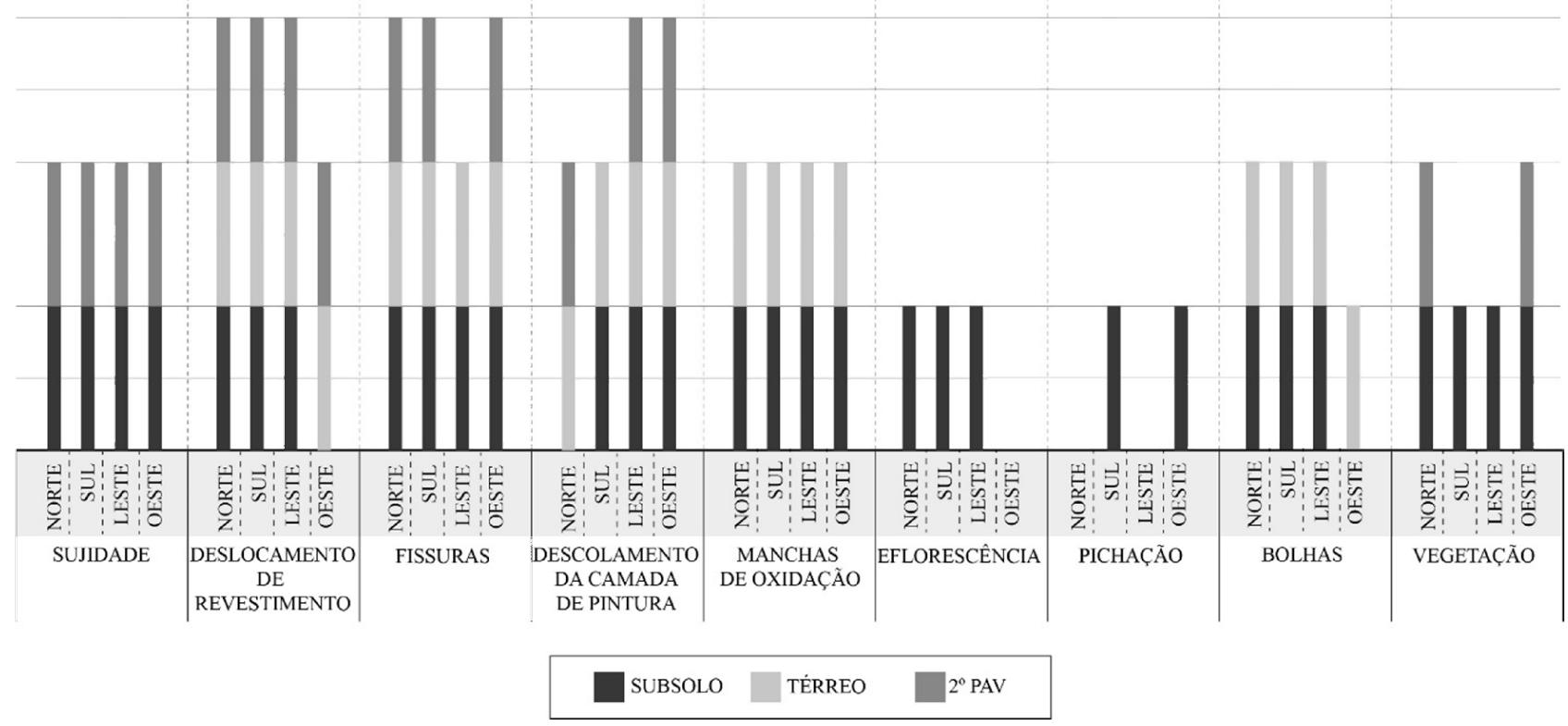

Figura 2: Ocorrência de manifestações patológicas nas fachadas da Biblioteca Central.

As fachadas do segundo pavimento são revestidas pelo material chamado fulget, material composto de agregados de pedra, cimento, e plastificantes, semelhante à granitina (Francelino, 2012). Devido ao seu aspecto rugoso, esse material possui alta aderência à sujidade, favorecendo o acúmulo de partículas carregadas pelo vento, como pode ser visto na Figura $3 \mathrm{a}$.

A falta de manutenção periódica nesse revestimento colaborou para a alteração da coloração do material, tornando-o com aspecto acinzentado. Na Figura 3b é possível visualizar a diferença nas áreas nas quais se executou uma limpeza em 2017, que não pôde ser continuada pela falta de acesso dos andaimes a alguns locais, evidenciando a presença da anomalia.
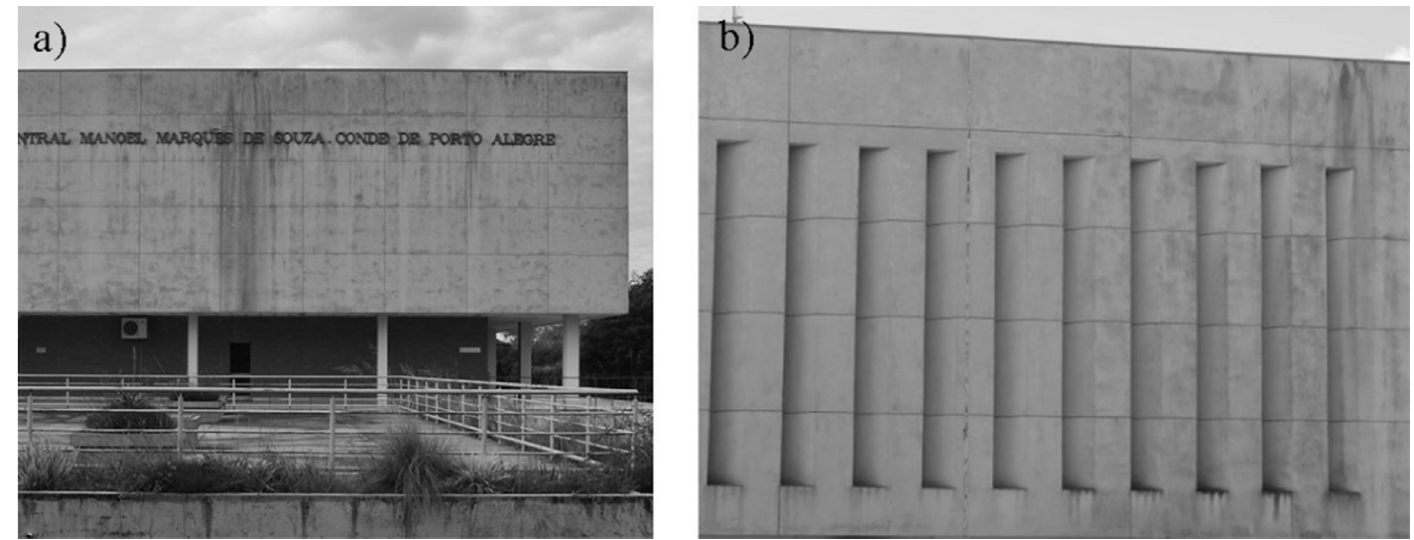

Figura 3: a) Sujidade no $2^{\circ}$ pavimento da fachada oeste; b) Diferença entre área de fachada na qual houve realização de limpeza.

Além disso, notou-se o desgaste e o descolamento de parte dos rejuntes das peças cerâmicas que compõem as pingadeiras das aberturas localizadas nas orientações leste, norte e oeste do segundo pavimento. Esse desgaste facilita e direciona o escoamento da água incidente na fachada, como mostra a Figura 4a, carregando partículas causadoras de manchas de sujeira.

No pavimento térreo, não foi identificada sujidade aparente, a não ser nos elementos de iluminação zenital (considerados pertencentes à fachada do térreo). Acredita-se que o deslocamento (recuo) da fachada, que configura um corredor coberto no entorno da edificação (Figura 4b), impeça o contato intenso dos ventos e água da chuva.

Já nas fachadas originais do subsolo, a incidência de sujidade ocorre com maior intensidade no perímetro da edificação. A Figura 4c destaca as regiões afetadas, abaixo da pingadeira configurada pela soleira do pavimento térreo e 
pingadeiras das aberturas.
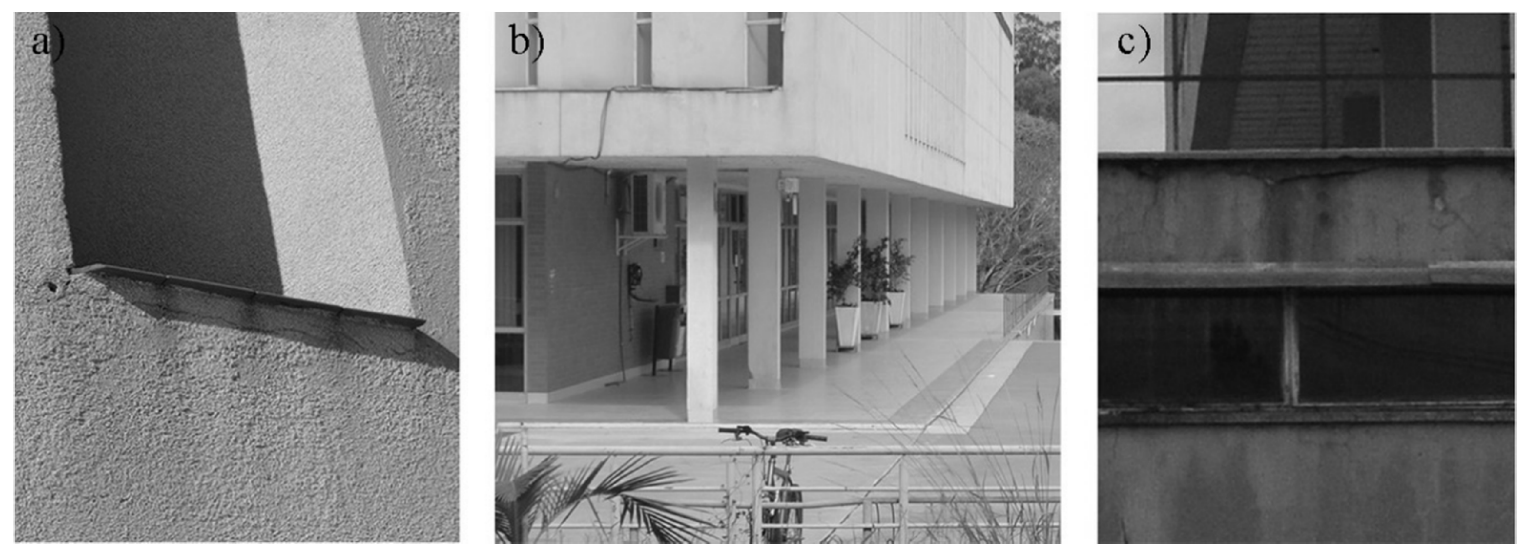

Figura 4: a) Sujidade abaixo de pingadeira do $2^{\circ}$ pavimento; b) Pavimento térreo recuado; c) Sujidade no subsolo.

Originalmente, o piso do primeiro pavimento consistia-se de lajota cimentícia com soleira de granitina em todo o perímetro da edificação, que posteriormente foi removido, sendo colocado um revestimento cerâmico convencional sobre uma manta asfáltica. A possível má execução dessa manta pode ter causado infiltrações, exigindo a aplicação de uma camada de resina com fibra de vidro, com posterior camada de tinta epóxi como acabamento. Diante disso, acredita-se que as manchas de sujeira tenham sido causadas a partir das mudanças ocorridas no piso externo do pavimento térreo, comprometendo algumas regiões com umidade excessiva, má drenagem da água da chuva e acúmulo de partículas.

Entretanto, a maior incidência de sujidade no subsolo ocorre na área ampliada, delimitada superiormente por floreiras em concreto aparente (Figura 5a), que integram a área externa do pavimento térreo. Essas floreiras foram projetadas para portar espécies de vegetação pendente, com o intuito de contribuir para a proteção solar do acervo. Apesar de serem impermeabilizadas com uma camada de fibra de vidro, não possuem pingadeiras, permitindo que a água percorra a parede, criando manchas de sujidade e cristais de sais nas contravergas das janelas do acervo (Figura 5b).
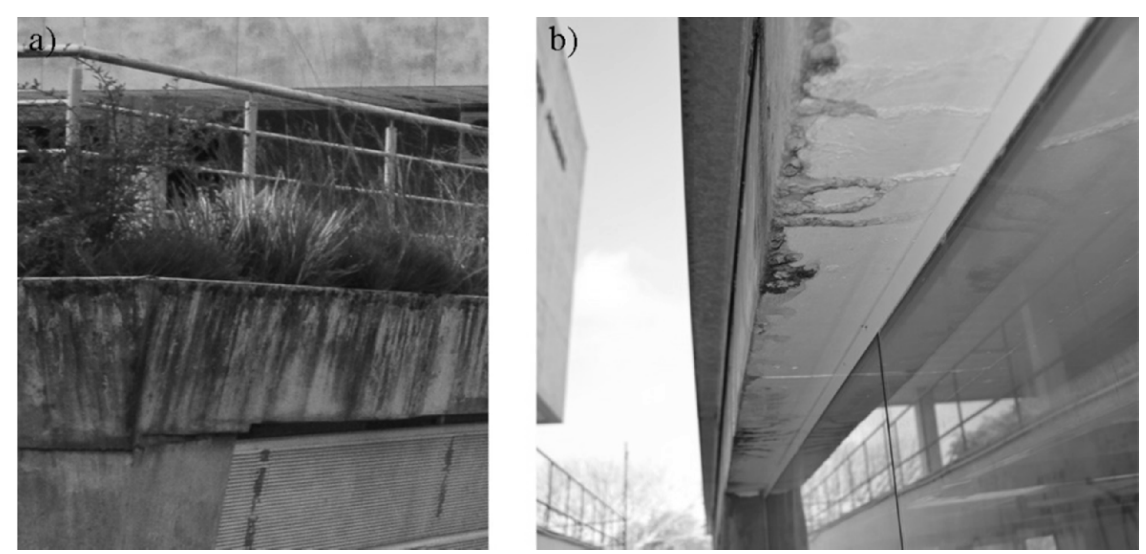

Figura 5: a) Sujidade em floreiras do subsolo; b) Formação de cristais de sais.

Ainda, percebeu-se a presença de sujidade em locais pontuais, com causas específicas. Exemplo disso é a fiação aparente na fachada norte abaixo da pingadeira de granitina, próxima à escada que conecta as áreas externas do subsolo e térreo, como mostra a Figura 6a, conduzindo a água por sua extensão, escorrendo linearmente pela fachada. Da mesma forma, a Figura $6 \mathrm{~b}$ demonstra a presença de manchas de sujeira nas áreas adjacentes aos drenos em PVC das floreiras.

Já o aparecimento de fissuras na edificação ocorre de forma não uniforme, afetando as áreas de revestimento com pintura no subsolo original, e áreas específicas das fachadas do segundo pavimento, bem como os fechamentos verticais dos elementos de iluminação zenital da área externa do térreo. 

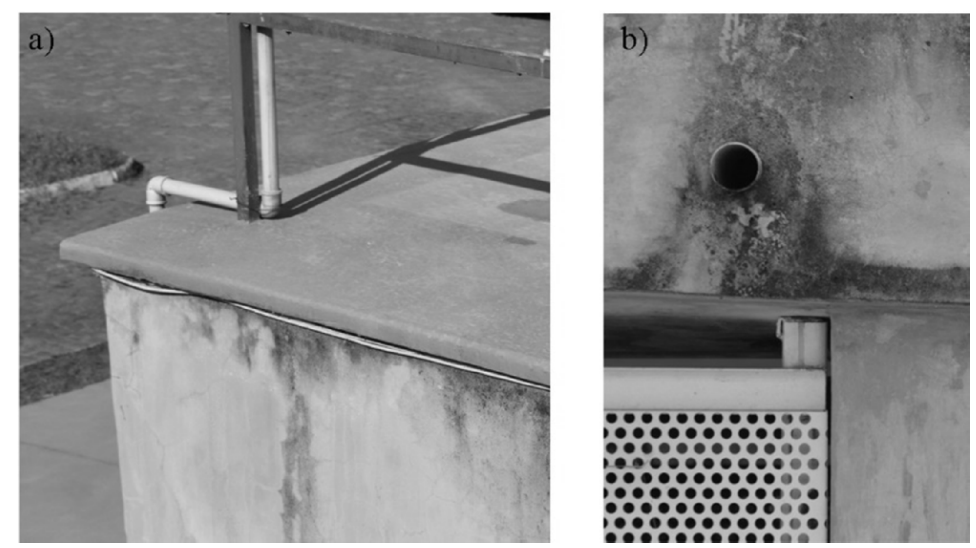

Figura 6: a) Sujidade pontual por fiação externa; b) Sujidade pontual abaixo de tubulação de PVC.

No subsolo original da Biblioteca Central, as fissuras têm por causa provável a falta de manutenção na pintura, visto que ocorrem nas fachadas de menor incidência solar, sul e leste, gerando um aspecto craquelado desse revestimento. Esse fato pode ter sido agravado pela composição do reboco, com provável consumo de cimento superior ao adequado, formando um revestimento com alta resistência e pouca flexibilidade. É importante salientar que o revestimento argamassado das fachadas do subsolo original foi executado sobre um primeiro revestimento em pedra, o que ainda pode ser visualizado nas fachadas leste e norte, nas quais se observa abertura de espaços entre os dois tipos de revestimentos, que facilitam o ingresso de umidade entre as camadas.

Entretanto, no pavimento térreo, há a intensificação dessa anomalia nas fachadas oeste e norte nos elementos de iluminação zenital, devido à maior incidência solar, provocando maior variação de temperatura. Ainda, acredita-se que o contato com a água da chuva acumulada nessa área colabora para o aparecimento de fissuras, propiciando também outros tipos de manifestações patológicas.

$\mathrm{O}$ aparecimento de fissuras superficiais no revestimento do segundo pavimento tem como causa provável a incidência solar direta, considerando a localização das mesmas em unidades distintas do revestimento em fulget. Ainda, identificou-se a ocorrência de fissuras com maior abertura e profundidade, desenvolvendo-se horizontalmente em locais específicos, como abaixo das aberturas e na altura provável de contato entre a viga de concreto armado e o revestimento argamassado. $\mathrm{O}$ trabalho diferenciado de dilatação térmica entre esses materiais é a causa possível para esse tipo de manifestação, acentuado pelo posterior ingresso de umidade.

Com menor incidência, mas ainda significativa, as eflorescências identificadas na edificação possuem forte relação com problemas já mencionados. O provável ingresso de umidade pelas fissuras e revestimentos descolados pode facilitar o contato da água com o sistema de alvenaria dos fechamentos verticais da edificação, que tende a evaporar e depositar soluções aquosas salinizadas na superfície.

Diante disso, foram identificados pontos de depósitos cristalinos, caracterizados por manchas de coloração esbranquiçada, no subsolo das fachadas leste (Figura 7a) e sul do edifício original da Biblioteca Central, como pode ser visto nas Figura 7b, Figura 7c e Figura 7d.

A Figura 8c ressalta, ainda, a presença de saponificação, com a desagregação e descascamento da camada de pintura. Essa manifestação patológica pode estar relacionada às eflorescências adjacentes e à presença de umidade nessa área da fachada leste do subsolo.

Foram identificadas, ainda, bolhas no subsolo da parte antiga da edificação e nos elementos de iluminação zenital localizadas no térreo. Essas manifestações patológicas são caracterizadas pelo estufamento sem perfuração da camada de pintura. Problemas de execução dessa camada como condições não ideais de umidade da base argamassada e presença de poeira podem estar relacionados com o aparecimento desse tipo de manifestação, comprometendo a aderência do revestimento. A mesma pode também estar associada às características da tinta utilizada, não permitindo a evaporação de umidade. 

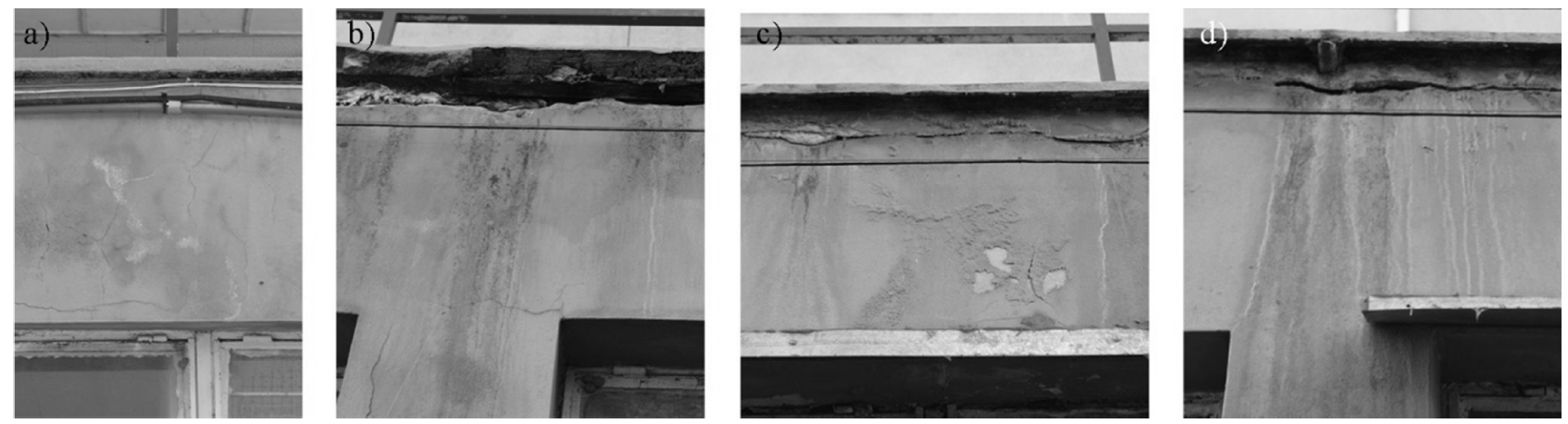

Figura 7: a) Eflorescência no subsolo da fachada leste; b) Eflorescência no subsolo da fachada sul; c) Eflorescência no subsolo da fachada sul, evidenciando saponificação; d) Eflorescência no subsolo da fachada sul, evidenciando umidade.

Podendo ser a etapa posterior ao surgimento das bolhas, e possuindo causas compartilhadas, puderam-se identificar vários locais onde houve o descolamento da camada de pintura. As áreas mais afetadas por essa anomalia são as fachadas do subsolo original, mostrada na Figura 8a, e os fechamentos verticais dos domos, na Figura 8b.

Ainda, observou-se o descolamento da camada de pintura em elementos metálicos. Como demonstrado na Figura 8c, os caixilhos das esquadrias das fachadas norte, leste e oeste do segundo pavimento, bem como da edificação original do subsolo, apresentam essa anomalia. Como causa provável aponta-se a falta de manutenção e consequente oxidação do aço, que intensifica o descolamento do revestimento. Já nas áreas da ampliação do subsolo, essa manifestação tem ocorrência pontual nos brises metálicos (Figura 8d), devido, provavelmente, às diferenças de dilatação entre a estrutura do protetor solar e a camada de pintura.
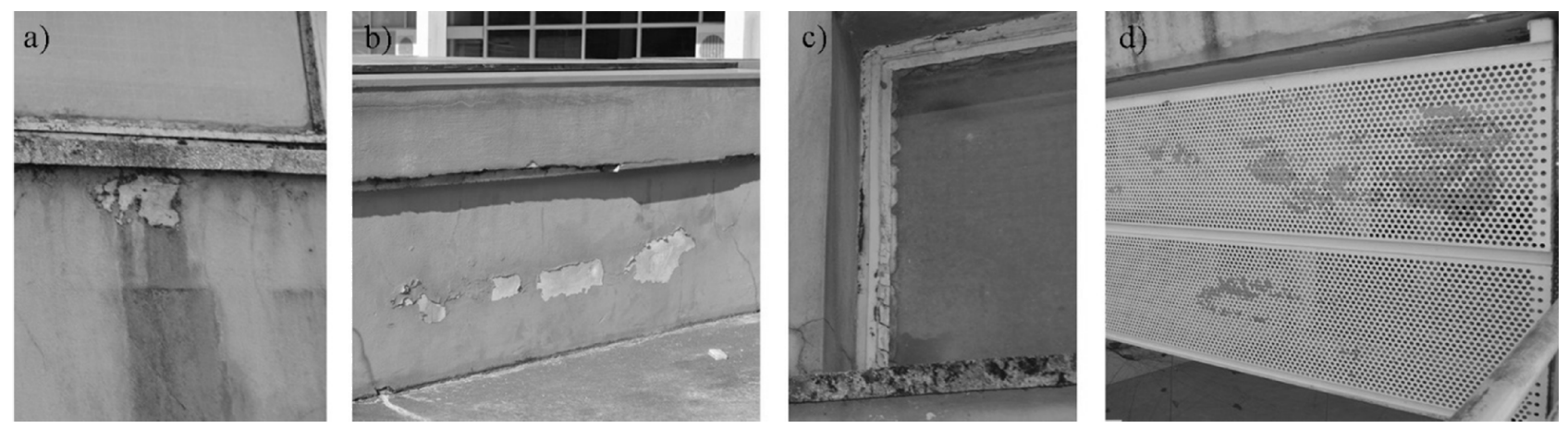

Figura 8: a) Descolamento de pintura abaixo de pingadeira no subsolo; b) Descolamento de pintura nos domos;

c) Descolamento de pintura em caixilho metálico; d) Descolamento de pintura em estrutura de proteção solar.

O descolamento do revestimento também foi identificado como uma das anomalias. Em razão da sujidade ocorrente no segundo pavimento, uma limpeza com lava jato foi realizada, sendo a causa provável da desagregação parcial de compostos do revestimento, conforme a Figura 9a. Notou-se que esse descolamento ocorreu de forma diferenciada nas fachadas, sendo a orientação norte visivelmente mais afetada. Acredita-se que a ação mecânica do jato de água atrelada à incidência solar diária, proporcionando maiores variações de temperatura e ressecamento do material, tenha contribuído para essa manifestação.

No pavimento térreo, a maior incidência de descolamento da camada de argamassa ocorre nos elementos de iluminação zenital (Figura 9b). Possivelmente a má execução (tempo de cura) aliada ao mau dimensionamento das pingadeiras dessa estrutura colaborou para a desagregação de tal camada. Além disso, o uso dessas estruturas como obstáculos para a prática do esqueitismo pode ter contribuído para o aparecimento dessa anomalia, devido ao impacto e sobrecarga linear nos elementos.

Foram também identificadas nas fachadas do edifício manchas de oxidação, incidentes nos caixilhos metálicos das esquadrias originais, onde ocorreu o descolamento da camada de pintura que pode ter possibilitado o ingresso de água, como pode ser observado na Figura 8c. Assim, o contato da água com o metal, torna-se, provavelmente, a causa principal da anomalia. 

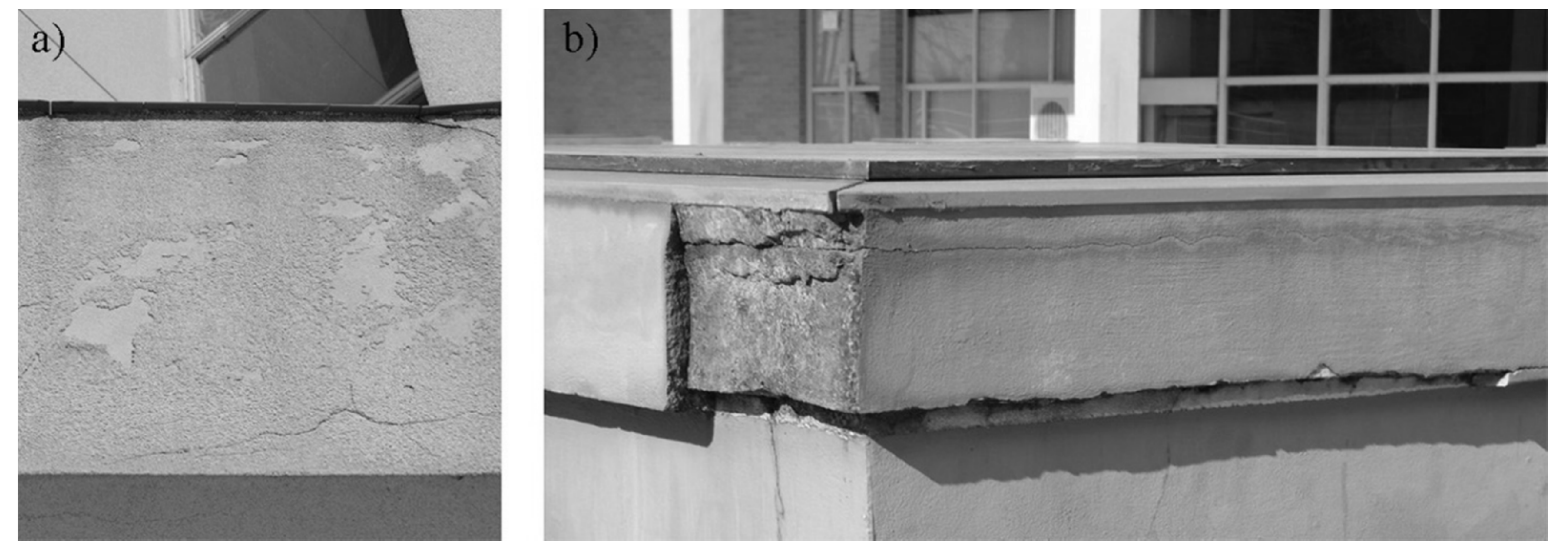

Figura 9: a) Desagregação de revestimento no $2^{\circ}$ pavimento; b) Descolamento de revestimento argamassado nos elementos de iluminação zenital.

Da mesma forma, essa manifestação ocorre nas fachadas da ampliação do subsolo, principalmente na região de drenos em PVC bem como na de fissuras entre as peças de concreto. Acredita-se que esses meios possibilitam o contato da água com a armadura metálica das estruturas de concreto, conduzindo as partículas referentes à oxidação.

Atos de vandalismo também estão presentes na edificação, principalmente nas fachadas sul do edifício original e na área oeste da rampa de acesso do pavimento térreo ao restaurante universitário da instituição. Essas regiões são caracterizadas por menor visibilidade, configurando um ambiente favorável a esse tipo de ação.

Por fim, em consequência da presença de umidade, acúmulo de matéria orgânica e falta de manutenção de locais como pingadeiras, notou-se o crescimento da micro e macro flora. Devido à menor incidência de sol, a fachada sul é mais afetada, com a presença de liquens, musgos e vegetações de pequeno porte. Todas estão localizadas nas pingadeiras das aberturas do subsolo (Figura 10a, Figura 10b e Figura 10c), caracterizadas, atualmente, por um material poroso e com rugosidade, facilitando o desenvolvimento de pequenas raízes. Já nas fachadas norte e oeste, a vegetação desenvolve-se, isoladamente, no entorno das aberturas, como mostra a Figura 10d.
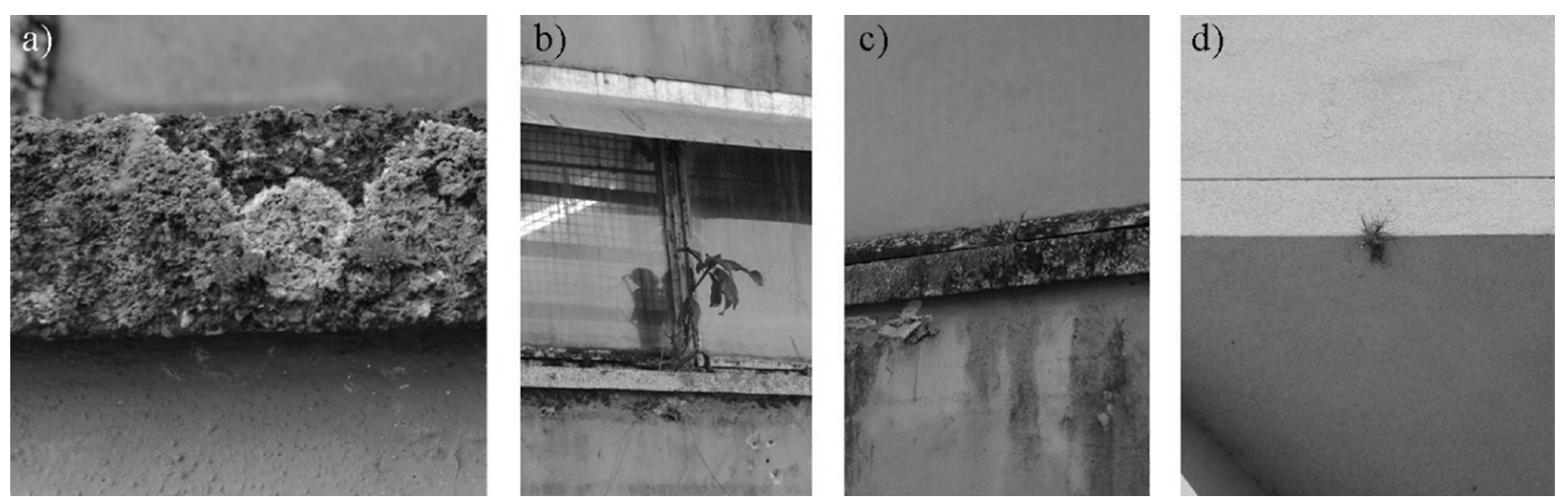

Figura 10: a) Microflora em pingadeira no subsolo da fachada sul; b) Vegetação em abertura localizada no subsolo da fachada sul; c) Macro e microflora em pingadeira do subsolo da fachada leste; d) Vegetação na área de abertura o segundo pavimento da fachada norte.

Outras manifestações patológicas foram identificadas, porém com menor incidência, não sendo consideradas na presente análise. Como exemplo, o descolamento de juntas de dilatação do revestimento em fulget, do segundo pavimento, principalmente nas fachadas leste e norte; marcas de contato de andaimes utilizados na limpeza desse mesmo revestimento; infiltração na junta de dilatação da rampa de acesso de veículos, localizada sobre a face interna do fechamento vertical do subsolo; desagregação do agregado de elementos em concreto aparente, permitindo o ingresso de umidade. 


\section{CONSIDERAÇÕES FINAIS}

Considerando a importância histórica e arquitetônica que a edificação da Biblioteca Central da UFSM apresenta, este trabalho teve como objetivo identificar as principais manifestações patológicas em suas fachadas, a fim de principiar análises que poderão ser usadas em uma futura manutenção na edificação. Por meio de pesquisa bibliográfica a respeito de patologia de edificações, anamnese e levantamento in loco, foi possível investigar essas anomalias e determinar suas causas mais prováveis.

A partir disso, pode-se dizer que as fachadas dessa edificação apresentam atualmente diversas manifestações patológicas, que vêm prejudicando sua integridade estética como símbolo da arquitetura moderna no Rio Grande do Sul. Entre elas destacam-se: sujidade, fissuras, eflorescência, bolhas, destacamento da camada de pintura, deslocamento de revestimentos, manchas de oxidação, pichação e vegetação.

A pesquisa identificou que em relação à edificação original, as causas possíveis mais recorrentes estão atreladas a intervenções inadequadas e falta de manutenção em conjunto com as ações do tempo. Nesse sentido, a ocorrência das anomalias tem forte relação com os sistemas e materiais construtivos, bem como a época de construção. Assim, a arquitetura moderna na qual se insere a Biblioteca Central também é entendida como impulsionadora para o aparecimento das manifestações patológicas citadas. Isso se deve à supressão de ornamentos das fachadas característicos da arquitetura colonial brasileira, como elementos lineares acima das aberturas (cimalha), beiras em todo o perímetro da edificação e bases mais alargadas. Logo, propicia-se a maior incidência de manchas e sujidade, uma vez que a água da chuva e os poluentes atmosféricos escorrem em contato direto com a parede.

Já a área de ampliação possui, principalmente, anomalias referentes a problemas de projeto e execução, evidenciando o planejamento inadequado dessas etapas para a intervenção em edificação já existente e com características históricas importantes. Vale ressaltar que as manifestações patológicas mais aparentes nessa parte da edificação podem ser mitigadas através das mesmas intervenções necessárias na parte original da mesma: manutenção das pingadeiras, recuperação do revestimento argamassado, pintura e limpeza adequadas. Ainda que essas medidas não solucionem completamente os problemas observados, são imprescindíveis para comedi-los e evitar que se tornem maiores e definitivos, sendo assim os mais urgentes.

Além disso, a Biblioteca Central da UFSM reflete hoje uma situação de completo descaso que ocorre também com outras edificações públicas de valor histórico no Brasil. Essas edificações padecem não somente das ações do tempo, mas também da falta de manutenção de diferentes instalações que podem resultar em danos irreversíveis, a exemplo do incêndio ocorrido em 2018 no Museu Nacional do Brasil.

Desse modo, é importante reforçar a necessidade de medidas de conservação para a Biblioteca Central, priorizando a execução de manutenções periódicas que auxiliem na durabilidade dos elementos e, consequentemente, na integridade funcional e arquitetônica da edificação como um todo. Espera-se que, através desse enfoque, os órgãos responsáveis atentem para a necessidade de interveção na edificação, incentivando, assim, investimentos para a preservação de um patrimônio arquitetônico pertencente à instituição.

\section{AGRADECIMENTOS}

Agradecemos à Coordenação de Aperfeiçoamento de Pessoal de Nível Superior - Brasil (CAPES) - pela concessão de bolsa de mestrado.

\section{REFERÊNCIAS}

ARABIDIAN, L. V.; CONSTANTE, S. E.; WOLLE, A. B. A arquitetura da Biblioteca Central da Universidade Federal de Santa Maria e o impacto na preservação do acervo. Perspectivas em Ciência da Informação, v. 20, n.1, p. 37-53, jan./mar. 2015. Disponível em: <http://www.scielo.br/scielo.php?script=sci_arttext\&pid=S141399362015000100037\&lng=pt\&tlng=pt $>$. Acesso em: 4 jun. 2018.

ARRUSSUL, L. G. Arquitetura, Urbanismo, Educação: O Campus da Universidade Federal de Santa Maria. 2009. 166 f. Dissertação (Mestrado em Urbanismo, História e Arquitetura da Cidade) - Universidade Federal de Santa Catarina, Florianópolis, SC, 2009. 166 p. Disponível em: < https://repositorio.ufsc.br/handle/123456789/106644>. Acesso em: 28 abr. 2018. 
BEASLEY, K. J. Identification And Diagnosis Of Building Façade Failures. In: FORENSIC ENGINEERING CONGRESS, 5., 2009, Washington. Proceedings... [S. 1.]: ASCE, 2009. p. 74 - 84. Disponível em: < https://ascelibrary-org.ez47.periodicos.capes.gov.br/doi/pdf/10.1061/41082\%28362\%298>. Acesso em 27 jun. 2018.

CHIARElli, C.; MICHelotTI, P. Obras na Biblioteca Central. Revista TXT, Santa Maria, n.13, p. 16-17, mai 2013. Disponível em: < http://coral.ufsm.br/revistatxt/?p=259>. Acesso em: 20 jul. 2018.

CONSOLI, O. J. Análise Da Durabilidade dos Componentes das Fachadas de Edifícios, Sob a Ótica do Projeto Arquitetônico. 2006. 208 f. Dissertação (Mestrado em Engenharia Civil) - Universidade Federal de Santa Catarina, Florianópolis, $2006 . \quad$ Disponível em: $<$ https://repositorio.ufsc.br/bitstream/handle/123456789/88380/239904.pdf?sequence=1\&isAllowed=y $>$. Acesso em: 27 abr. 2018.

FERRAZ, G. T. et al. Sistemas de gestão técnica integrada de edifícios: inspecção e reparação de elementos não estruturais. Revista ALCONPAT, [S. 1.], v. 5, n. 2, p. 137 - 148, may./ago. 2015. Disponível em: $<$ revistaalconpat.org/index.php/RA/article/download/83/98>. Acesso em: 27 jun. 2018.

FRANCELINO, P. R. O. Subsídios para projeto e execução de revestimentos em granilite. 2012. 182 f. Dissertação (Mestrado em Engenharia Civil) - Universidade de São Paulo, São Carlos, 2012. Disponível em: $<$ http://www.teses.usp.br/teses/disponiveis/18/18134/tde-14052012-091942/en.php>. Acesso em: 20 jul. 2018.

LERSCH, I. M. Contribuição para a Identificação dos Principais Fatores e Mecanismos de Degradação em Edificações do Patrimônio Cultural de Porto Alegre. 2003. 185 f. Dissertação (Mestrado em Engenharia Civil) Universidade Federal do Rio Grande do Sul, Porto Alegre, 2003. Disponível em: $<$ http://www.lume.ufrgs.br/handle/10183/3674>. Acesso em: 27 abr. 2018.

LIMA, G. E. S.; SOUZA K. D.; TIBIRIÇÁ, A. C. G. Investigação e Diagnóstico de Patologias Relacionadas às Fachadas de Uma Edificação. In: ENCONTRO NACIONAL DE TECNOLOGIA DO AMBIENTE CONSTRUÍDO, 15., 2014, Maceió/AL. Anais... Maceió: ANTAC, 2014, p. 1715-1724. Disponível em: $<$ http://www.infohab.org.br/entac2014/artigos/paper_472.pdf>. Acesso em: 28 abr. 2018.

MADUREIRA, S. et al. Maintenance planning of facades in current buildings. Construction and Building Materials, Lisboa, v. $147, \quad$ p. $790 \quad-\quad 802, \quad$ may $2017 . \quad$ Disponível em: $<$ https://drive.google.com/drive/folders/1pzBQE6jLaJfnTIgQHiPKjrmUNVIKGQVC>. Acesso em: 27 abr. 2018.

MAGALHÃES et al. 2008. Methodology for diagnosis of rendering analies due to moisture in walls. Conservar Património, [S.1], n. 7, p. 45-54. 2008. Disponível em: < http://revista.arp.org.pt/pdf/7_6.pdf>. Acesso em: 27 jun. 2018.

MAZER, W. et al. Avaliação de manifestações patológicas em edifícios em função da orientação geográfica. Revista ALCONPAT, [S. 1.], v. 6, n. 2, p. 145 - 156, may./ago. 2016. Disponível em: $<$ http://revistaalconpat.org/index.php/RA/article/viewFile/135/168>. Acesso em: 12 maio 2018.

MUller, S. R. Histórico do Campus e as Patologias das Fachadas dos Prédios Voltados para a Avenida Roraima - UFSM. 2010. 120 f. Dissertação (Mestrado em Engenharia Civil) - Universidade Federal de Santa Maria, Santa Maria, 2010. Disponível em: $<$ https://repositorio.ufsm.br/bitstream/handle/1/7755/MULLER\%2c\%20SIOMARA\%20RIBEIRO.pdf?sequence=1\&is Allowed=y>. Acesso em: 28 abr. 2018.

OLIVEIRA, C. S. P. Análise Crítica de Experiências e Discussão de Estratégias para Implantação de Leis de Inspeção de Elementos de Fachadas. 2013. 220 f. Tese (Doutorado em Engenharia Civil) - Universidade Federal do Rio Grande do Sul, Porto Alegre, RS, 2013. Disponível em: <http://www.lume.ufrgs.br/handle/10183/79846>. Acesso em: 12 maio 2018.

PEREIRA, L. M. Avaliação das Patologias e da Biodeteriorização na Biblioteca Central da UFSM. 2012.126 f. Dissertação (Mestrado em Engenharia Civil e Ambiental) - Universidade Federal de Santa Maria, Santa Maria, 2012. Disponível 
$<$ https://repositorio.ufsm.br/bitstream/handle/1/7808/PEREIRA\%2C\%20LUCIANA\%20MANZONI.pdf?sequence=1\&i sAllowed=y>. Acesso em: 25 abr. 2018.

PIRES, R.; BRITO, J.; AMARO, B. Inspection, Diagnosis, and Rehabilitation System of Painted Rendered Façades. Journal of Performance of Constructed Facilities, [S. 1.], v. 29, n. 2, 1 apr. 2015. Disponível em: $<$ https://ascelibrary-org.ez47.periodicos.capes.gov.br/doi/pdf/10.1061/\%28ASCE\%29CF.1943-5509.0000534>. Acesso em: 27 jun. 2018.

SÁ, G. et al. Inspection and diagnosis system for rendered walls. International Journal of Civil Engineering, [S. 1.], v. 12, n. 2, jun. 2014. Disponível em: <http://ijce.iust.ac.ir/browse.php?a_id=738\&sid=1\&slc_lang=en>. Acesso em: 27 jun. 2018.

SCHLEE, A. R. Reproduzindo modelos: O plano piloto do campus da Universidade Federal de Santa Maria, RS. In: SEMINÁRIO DOCOMOMO BRASIL, 5., 2003, São Carlos. Anais... São Carlos, 2003. Disponível em: $<$ http://docomomo.org.br/wp-content/uploads/2016/01/020R.pdf >. Acesso em: 28 abr 2012.

TREULIEB, L. 40 anos da Biblioteca Central: um prédio cheio de histórias, UFSM, Santa Maria, 2012. Disponível em: $<$ https://www.ufsm.br/2012/08/31/40-anos-da-biblioteca-central-um-predio-cheio-de-historias/>. Acesso em junho de 2018.

UNIVERSIDADE FEDERAL DE SANTA MARIA. UFSM em Números: Painel Alunos. UFSM, Santa Maria, 23 jun. 2018. Disponível em: <https://portal.ufsm.br/ufsm-em-numeros/publico/painel.html?categoria=101>. Acesso em: 23 jun. 2018.

ZAMPIERI R. V.; MACHADO, A. S. A UFSM e uma possível preservação através da interdisciplinaridade. In: SEMINÁRIO DOCOMOMO BRASIL, 9., 2011, Brasília. Anais eletrônicos... Brasília, 2011 Disponível em: $<$ http://docomomo.org.br/wp-content/uploads/2016/01/066_PB_OR-AUFSM-ART_renata_zampiere.pdf $>$. Acesso em: 27 jun 2018.

ZAMPIERI, R. V. Campus da Universidade Federal de Santa Maria: um testemunho, um fragmento. $2011.220 \mathrm{f}$. Dissertação (Mestrado em Arquitetura) - Universidade Federal do Rio Grande do Sul, Porto Alegre, 2011. Disponível em: <http://www.lume.ufrgs.br/handle/10183/36824>. Acesso em: 25 abr. 2018. 